\title{
Predictive accuracy of APACHE II score in predicting mortality in poly Trauma patients.
}

1. MBBS

Registrar Surgery

Lahore General Hospital, Lahore.

2. MBBS, FCPS

Assistant Professor Surgery

Ameer-ud-din Medical College,

Lahore.

3. MBBS, FCPS

Assistant Professor Surgery

Ameer-ud-din Medical College,

Lahore.

4. MBBS, MS

Senior Registrar Surgery

Ameer-ud-din Medical College, Lahore.

5. MBBS

Registrar Surgery

Lahore General Hospital, Lahore.

6. MBBS

House Officer

Lahore General Hospital, Lahore

Correspondence Address:

Dr. Muhammad Kareem Ullah

Department of Surgery

Ameer-ud-din Medical College,

Lahore.

dr.karimullah74@gmail.com

Article received on:

12/08/2021

Accepted for publication:

20/10/2021

\section{INTRODUCTION}

Trauma is defined when a body is injured or fractured due to external factors, it resulted more than 600,000 deaths globally and many become disabled throughout their life. ${ }^{1}$ Poly-trauma can be defined as the injury or accident that caused damage to minimum of two different organs or systems. While one of that injury can be risk to life. It is the accumulation of anatomical as well as physiological deficiencies and there progression is difficult to expect and usually have questionable consequences. ${ }^{2}$ The prevalence of poly-trauma is reported $10 \%{ }^{2}$ and these patients are at high risk to die due to acute deterioration of function after a high magnitude injury within the first hour. ${ }^{3}$

The preliminary evaluation and treatment of such serious injuries is the most challenging task. It needs a quick and efficient approach. There have been several severity scores introduced previously while only few of them are applied. Many scoring systems can be estimated by the data collected during first day at hospital including APACHE, Simplified Acute Physiology Score (SAPS), \& Mortality Prediction Model (MPM). ${ }^{5}$

APACHE II is a severity-of-disease classification system, APACHE II was purpose fully planned to measure the severity of disease for adult patients admitted to intensive care units. ${ }^{6,122}$ It is described that the APACHE II has sensitivity and specificity of $88 \% / 90 \%$ respectively with an accuracy of $90 \% .{ }^{4}$ But some of the workers do not agree and figures regarding sensitivity. Specificity and accuracy have been mentioned as low as $82.5 \%$, $55.2 \%$ and $66 \%$ respectively. ${ }^{5}$

Trauma is still a "major killing factor" in young 
adults of age $<45$ years all over the world. ${ }^{8,9}$ Mortality related to trauma is caused by three major reasons: (1) sudden death at accident site because of disastrous injuries like rupture of the aorta with major hemorrhage, brain stem tears or amputating injury; (2) initial death within minutes to hours (golden hours of management) because of airway obstruction, pneumothorax (tension), hemorrhage leading to shock as a result of intra-abdominal or intra-thoracic bleeding and also pelvic ring disturbances with enormous haemorrhage in the retroperitoneum, or because of severe brain injury with intracranial haematoma or edema; (3) late death in next few days or weeks because of sepsis, multiple organs failure and raised intracranial pressure linked with cerebral edema, which is untreatable. ${ }^{10}$

Despite the improved traffic and job-related safety, and also the momentous advancement in management of trauma victims according to the ATLS protocol, high grade trauma represents the most common cause of mortality. Instant and premature trauma-related mortality can be determined due to severe brain injuries or major blood loss after penetrating or blunt injuries. Late deaths is caused by secondary brain injuries and failure in host defense. ${ }^{11}$

Direct or indirect machine-driven forces persuade organs and soft tissue injuries. But, these first trauma represents the greater challenge, as local tissue damage, like lacerations or contusions, hypotension and hypoxia, persuade further systemic and local responses, in order to safeguard the immune system reliability and drive reparative mechanisms. ${ }^{12}$

The rationale of our study is to assess the clinical importance of APACHE II score in poly trauma patients in terms of 24 hours in hospital outcome. Due to considerable statistics of accidents and trauma related deaths in Lahore General Hospital, we need certainty of APACHE II scoring system to accurately predict the outcome of poly trauma patients for our own population as no local study is published and international data though gives consistent sensitivity ${ }^{4,5}$ but wide range of specificity $90 \%{ }^{4} 55.2 \% .{ }^{5}$ this study will help us for triage and to devise an efficient treatment plan for poly trauma patients to reduce the probability of hospital mortality.

To find diagnostic accuracy of APACHE II score in predicting mortality in poly Trauma patients within first 24 hours of hospitalization.

\section{MATERIAL \& METHODS}

This Cross sectional study was conducted at Emergency department of Lahore General Hospital, from October 2018 to October 2019. The study was reviewed and approved by Ethical Review Board (AMC/PGMI/LGH/Article/Research $\mathrm{No} / 03 / 30 / 21)$

The Non-probability consecutive sampling was used. We took 270 patients using sensitivity and specificity of APACHE II 82.5\%, 55.2\% $10 \%$ margin of error for sensitivity, respectively and $95 \%$ confidence level using $10 \%^{7}$ prevalence of poly trauma.

Patients presenting in emergency department with poly trauma (injuries involving more than one body system) aged 18-60 years of either gender were included in the study. Patients with major burn, concomitant cardiac injury were not included.

Two hundred and seventy patients who fulfill the criteria that we designed for selection were enrolled in the study from emergency department of Lahore General Hospital, informed consent were taken from all enrolled patients or their relatives to take their demographic profile and other necessary clinical data. To calculate APACHE II score, age, vitals, CBC levels, Glasgow coma scale score \& chronic health points was measured on patients' arrival. The APACHE II score (the minimum score is 0 and maximum is 71) is calculated from routine physiological measurements called acute physiology score (vital signs, laboratory values, Glasgow coma score), age, chronic health status of the patient and type of admission. These are calculated during the first 24 hours after admission. The most abnormal value is used to derive a score. Patient was classified as per their APACHE ॥ score. After calculating APACHE II score patients 
were managed according to trauma severity and followed up till 24 hours to note the in hospital mortality.

Data was entered \& analyzed through SPSS v. 20. Prevalence and percentages were analyzed for all qualitative variables like gender and in-hospital outcome (alive/mortality) on both APACHE II score and actual outcome. Mean \pm standard deviation was calculated for all quantitative variables like age and duration of injury and APACHE II score. 2 $\times 2$ tables were made and sensitivity, specificity, PPV \& NPV and overall accuracy was calculated.

\section{RESULTS}

The mean ages of patients were $38.53 \pm 11.67$ years. There were $173(63.91 \%)$ male and $97(36.09 \%)$ were female patients. The mean duration of injury was $4.64 \pm 3.76$ hours. A total of $28(10.43 \%)$ cases had injury since $<2$ hours, $155(57.39 \%)$ cases had injury since $2-4$ hours and $87(32.17 \%)$ cases had injury $>4$ hours. Table-I

Out of 270 cases in hospital mortality occurred in $99(36.5 \%)$ while other $171(63.5 \%)$ were alive within 24 hours of in hospital stay. According to APACHE II score, 99(36.5\%) cases had > 11.5 score and rests of $171(63.5 \%)$ had APACHE II $\leq$ 11.5. The sensitivity, specificity, PPV, NPV and diagnostic precession of APACHE II was $89.16 \%$, $93.2 \%, 88.1 \%, 93.84 \%$ and $91.74 \%$. Table-II

\begin{tabular}{|l|c|c|}
\hline \multicolumn{1}{|c|}{ Age } & Years & $38.53 \pm 11.67$ \\
\hline \multirow{3}{*}{ Gender } & Male & $97(36.09 \%)$ \\
\hline \multirow{3}{*}{$\begin{array}{l}\text { Duration of } \\
\text { injury }\end{array}$} & Female & $176(63.91 \%)$ \\
\hline \multirow{3}{*}{} & Hours & $4.64 \pm 3.76$ \\
\cline { 2 - 3 } & 2-4hours & $28(10.43 \%)$ \\
\hline & $>$ 4hours & $155(57.39 \%)$ \\
\hline
\end{tabular}

Table-I. Demographics of patients $(n=270)$

\begin{tabular}{|l|l|c|c|c|}
\hline \multicolumn{2}{|c|}{} & \multicolumn{2}{c}{ In Hospital Mortality } & \multirow{2}{*}{ Total } \\
\cline { 3 - 5 } & \multicolumn{1}{|c|}{ Yes } & No & \\
\hline APACHE II & $>11.5$ & $87(89.2 \%)$ & $12(6.8 \%)$ & $99(36.5 \%)$ \\
\hline score & $\leq 11.5$ & $10(10.8 \%)$ & $161(93.2 \%)$ & $171(63.5 \%)$ \\
\hline Total & & $97(100 \%)$ & $173(100 \%)$ & $270(100 \%)$ \\
\cline { 3 - 4 } & Table-II. Accuracy of APACHE-II Score
\end{tabular}

\section{DISCUSSION}

Trauma scoring systems are applied in routine to estimate and observe the prognosis of the traumatic injury. It is estimated to decrease the frequency of inevitable modalities. ${ }^{13}$ Disease severity scores are vital tools to study the prognosis of injured patients and to evaluate the efficiency of trauma centers. Primarily management method was to focus on assessment of the frequency of avoidable mortalities. But, due to increase in the occurrence of accidental trauma, several statistical models are developed in order to precisely forecast the sequel of patients presented with trauma. ${ }^{14}$ Every scoring system has its inherent positive and negative aspects. The preference of using any system depends on the comfort of its use and suitability for a specific intensive care department or group of patients. ${ }^{15}$

Knaus et al., popularized the "Acute Physiology and Chronic Health Evaluation" (APACHE) scoring system during 1981. This system was used to classify the intensity of the disease or injury and forecast the future sequel during course of treatment. ${ }^{16}$ Data collected during 1985, from 5815 admissions in medical and surgical intensive care units in 13 different hospitals was collected to improve APACHE-I into APACHEII. The APACHE-II scoring is organized on the basis of 12 physiological measurements done in routine along with the age of patient and health status before current event. ${ }^{17}$

APACHE-II based on variation in the normal functioning of the major organs systems. It is comparatively independent of the treatment given before admission in intensive care unit and particular disease developments. ${ }^{18}$ There are other scoring systems that has been introduced but up till now APACHE-II is applied for clinical research or audit. ${ }^{15} \mathrm{~A}$ retrospective study reported mean age: $39.2 \pm 16.2$, range: $16-88$ years in poly trauma cases. ${ }^{19} \mathrm{We}$ also found similar pattern i.e. the mean age of patients was $38.53 \pm 11.67$ years with $172(63.91 \%)$ male and $97(36.09 \%)$ were female patients. The male patients were more as they had more outdoor activity with high risk of trauma. 
Currently a prospective study is conducted to compare the efficiency of three admission prognostic marks in prediction of in-hospital mortality. Information of 9549 patients for admission characteristics and hospital outcome were recorded. The result showed that out of 9549 patients, 1276 (13.3\%) died during stay at intensive care department. Patient admission features were significantly different between both; survivors and non-survivors. ${ }^{20}$ In current study, we had highest mortality i.e. out of 270 cases in hospital mortality occurred in $97(36.1 \%)$ while other $171(63.5 \%)$ were alive within 24 hours of admission.

Likewise a retrospective study is carried out to assess the sensitivity and specificity of APCHE II as $90.91 \%$ and $72.50 \% .{ }^{21}$ In current study according to APACHE II score, 98(36.5\%) cases had $>11.5$ score and rests of $171(63.5 \%)$ had APACHE II $\leq 11.5$. The sensitivity, specificity, PPV, NPV and diagnostic precession of APACHE II was 89.16\%, 93.2\%, 88.1\%, 93.84\% and $91.74 \%$.

A study is done to compare the performance of APACHE-II score in the prediction of in-hospital death rate in cases of critically ill category. Around 1311 consecutive adults admitted in intensive care department in Western Australia were included in the study. The APACHE-II score had good standardization and judgment than Max SOFA (ROC $=0.858$ vs 0.829), admission SOFA (ROC $=0.858$ vs 0.791 ), and first day or augmenting 5-day RRPHICU organ failure score ( $R O C=0.858$ vs 0.822 and 0.819 , reciprocally) in the prediction of in-hospital death rate. The study reported that the APACHE II score predicted inhospital mortality of seriously ill patients better than SOFA and RPHICU. ${ }^{22}$

In a cohort study conducted during 2000, APACHE-II and Simplified Acute Physiology Score (SAPS) II scoring systems were compared in an intensive care department. Sample of 661 cases were included. In outcome of both systems had poor analysis and misjudged death rate. But both had good power of discrimination, while SAPS-II performed superior than APACHEII. The assessment of goodness of fit in several sub-groups established the arrangement of underestimation of mortality of both models and APACH-II performed superior than SAPS-II. Hence, it was concluded that APACHE-II can be a better predictor than SAPS-II. ${ }^{23}$

Another study done to estimate the applicability of APACHE-II system to determine prognosis of patient admitted in two different Canadian intensive care units. The expected possibility of mortality was estimated for every case by applying APACHE-II risk of death equation. It was observed that in 1724 patients mean APACHEII was $16.5 \pm 0.2$. The predicted mortality rate was $24.7 \%$ while observed mortality rate was $24.8 \%$. The area under $\mathrm{ROC}=0.86$. The sensitivity of APACHE-II was $50.9 \%$ while specificity was 93.6\%. It was observed that Canadian patients had high mortality rate \& APACHE-II score than patients of United States. ${ }^{24}$

In contrary to above stated study, another cohort study was done to figure out the daily use of APACHE-II to predict the mortality rate in intensive care department. Every day APACHE-II scores were computed for each patient and both; intensive care units and in-hospital death were forecasted. First day APACHE II scores was inbetween 0 to 55 (mean=18). Death rates were 158 (69\%) mortality per 229 patients, 68 (62\%) mortality per 110 patients, and 110 (48\%) deaths per 230 patients were estimated, respectively, for such criteria. Thus it was concluded that daily APACHE-II scores cannot predict the individual patient's death rate. ${ }^{25}$

One multi-centered cohort study was done to compare the ability of APACHE II in prediction of in-hospital outcome of 8724 patients admitted in intensive care department of clinical care centers in Britain \& Ireland. The frequency of overall correct classification of APACHE-II was $79 \%$. Therefore, APACHE-II established the higher degree of integrity of fit, which was superior to other scoring systems for patients admitted in intensive care department. ${ }^{26}$

Furthermore another study reported that the Mean APACHE II score of patients aged $53 \pm 16$ years, was $10.5 \pm 7.0$. The mean APACHE II score 
was significantly less among survivors i.e. 9.0 $\pm 5.2(n=1813)$ as compared to non-survivors i.e. $21.5 \pm 8.5(n=248) .{ }^{27}$ We mainly based on these studies which it APACHE II has sensitivity and specificity of $88 \%$ and $90 \%$ respectively with an accuracy of $90 \% .{ }^{4}$ But some of the workers do not agree and figures regarding sensitivity. Specificity and accuracy have been mentioned as low as $82.5 \%, 55.2 \%$ and $66 \%$ respectively. ${ }^{5}$ Our study had high diagnostic accuracy, so we use APACHE II to predict hospital outcome in our population.

\section{CONCLUSION}

According to the findings of this study, we found high precision of APACHE II for prediction of inhospital death rate with high sensitivity, specificity, PPV, NPV and diagnostic accuracy. Using APACHE II in future we can devise an efficient treatment plan for poly trauma patients to reduce the probability of hospital mortality.

Copyright $\Subset 20$ Oct, 2021.

\section{REFERENCES}

1. Norouzi V, Feizi I, Vatankhah S, Pourshaikhian M. Calculation of the probability of survival for trauma patients based on trauma score and the injury severity score model in fatemi hospital in ardabil. Archives of trauma research 2013; 2(1):30-5.

2. Aksamija G, Mulabdic A, Muhovic S. Quantiffication of polytrauma and Hospital Mortality in Clinical Center University of Sarajevo in five-year period. Materia Socio-Medica 2011; 23(2):81-3.

3. Mica L, Albrecht K, Keel M, Trentz O. Independent predictors of early death of polytrauma patients: An analysis of 696 patients. Trauma \& Treatment 2012; 1(3):1-5.

4. CERNEA D, Novac M, Drăgoescu P, STĂNCULESCU A, DUCA L, AL-ENEZY AA, et al. Polytrauma and Multiple Severity Scores. Current health sciences journal 2014; 40(4):244-8.

5. Halim DA, Murni TW, Redjeki IS. Comparison of Apache II, SOFA, and Modified SOFA scores in predicting mortality of surgical patients in intensive care unit at Dr. Hasan Sadikin General Hospital. Crit Care Shock 2009; 12(4):157-69.
6. Richards G, Levy H, Laterre P-F, Feldman C, Woodward B, Bates BM, et al. CURB-65, PSI, and APACHE II to assess mortality risk in patients with severe sepsis and community acquired pneumonia in PROWESS. Journal of intensive care medicine 2011; 26(1):34-40.

7. Aksamija G, Mulabdic A, Muhovic S. Quantiffication of polytrauma and Hospital Mortality in Clinical Center University of Sarajevo in five-year period. Materia Socio-Medica 2011; 23(2):81-3.

8. Bardenheuer M, Obertacke U, Waydhas C, Nast-Kolb D. Epidemiology of the severe multiple trauma-a prospective registration of preclinical and clinical supply. J Orthop Trauma 2000;14(6):453.

9. Rixen D, Raum M, Bouillon B, Schlosser L, Neugebauer $E$. [Predicting the outcome in severe injuries: an analysis of 2069 patients from the trauma register of the German Society of Traumatology (DGU)]. Unfallchirurg 2001; 104(3):230-9.

10. Trauma ACoSCo. Advanced trauma life support: ATLS: Student course manual: American College of Surgeons; 2004.

11. Acosta JA, Yang JC, Winchell RJ, Simons RK, Fortlage DA, Hollingsworth-Fridlund $P$, et al. Lethal injuries and time to death in a level I trauma center. J Am Coll Surg 1998; 186(5):528-33.

12. Rotstein OD. Modeling the two-hit hypothesis for evaluating strategies to prevent organ injury after shock/resuscitation. J Trauma 2003; 54(5):S203-S6.

13. Moon J-H, Seo B-R, Jang J-W, Lee J-K, Moon H-S. Evaluation of probability of survival using trauma and injury severity score method in severe neurotrauma patients. J Korean Neurosurg Soc 2013; 54(1):42-6.

14. Hwang SY, Lee JH, Lee YH, Hong CK, Sung AJ, Choi YC. Comparison of the Sequential Organ Failure Assessment, Acute Physiology and Chronic Health Evaluation II scoring system, and Trauma and Injury Severity Score method for predicting the outcomes of intensive care unit trauma patients. Am J Emerg Med 2012; 30(5):749-53.

15. Ho KM, Dobb GJ, Knuiman M, Finn J, Lee KY, Webb SA. A comparison of admission and worst 24-hour Acute Physiology and Chronic Health Evaluation II scores in predicting hospital mortality: A retrospective cohort study. Crit Care 2005; 10(1):1.

16. Knaus WA, Zimmerman JE, Wagner DP, Draper EA, Lawrence DE. APACHE-acute physiology and chronic health evaluation: A physiologically based classification system. Crit Care Med 1981; 9(8):591-7. 
17. Knaus WA, Draper EA, Wagner DP, Zimmerman JE. APACHE II: A severity of disease classification system. Crit Care Med 1985; 13(10):818-29.

18. Waters M, Nightingale $P$, Edwards J. A critical study of the APACHE II scoring system using earlier data collection. Emerg Med J 1990; 7(1):16-20.

19. Mica L, Furrer E, Keel M, Trentz O. Predictive ability of the ISS, NISS, and APACHE II score for SIRS and sepsis in polytrauma patients. Eur $\mathrm{J}$ Trauma Emerg Surg 2012; 38(6):665-71.

20. Ho KM, Williams TA, Harahsheh Y, Higgins TL. Using patient admission characteristics alone to predict mortality of critically ill patients: A comparison of 3 prognostic scores. J Crit Care 2016; 31(1):21-5.

21. Agarwal A, Agrawal A, Maheshwari R. Evaluation of probability of survival using APACHE II \& TRISS method in orthopaedic polytrauma patients in a tertiary care centre. J Clin Diagn Res 2015; 9(7):RC01.

22. Ho K, Lee K, Williams T, Finn J, Knuiman M, Webb S. Comparison of Acute Physiology and Chronic Health Evaluation (APACHE) II score with organ failure scores to predict hospital mortality. Anaesthesia 2007; 62(5):466-73.
23. Katsaragakis S, Papadimitropoulos $\mathrm{K}$, Antonakis $\mathrm{P}$, Strergiopoulos S, Konstadoulakis MM, Androulakis G. Comparison of Acute Physiology and Chronic Health Evaluation II (APACHE II) and Simplified Acute Physiology Score II (SAPS II) scoring systems in a single Greek intensive care unit. Crit Care Med 2000; 28(2):426-32.

24. Wong DT, Crofts SL, Gomez M, McGuire GP, Byrick RJ. Evaluation of predictive ability of APACHE II system and hospital outcome in Canadian intensive care unit patients. Crit Care Med 1995; 23(7):1177-83.

25. Rogers J, Fuller HD. Use of daily Acute Physiology and Chronic Health Evaluation (APACHE) II scores to predict individual patient survival rate. Crit Care Med 1994; 22(9):1402-5.

26. Rowan KM, Kerr JH, Major E, McPherson K, Short A, Vessey MP. Intensive Care Society's Acute Physiology and Chronic Health Evaluation (APACHE II) study in Britain and Ireland: A prospective, multicenter, cohort study comparing two methods for predicting outcome for adult intensive care patients. Crit Care Med 1994; 22(9):1392-401.

27. BERGER MM, MARAZZI A, FREEMAN J, CHIOLÉRO R. Evaluation of the consistency of Acute Physiology and Chronic Health Evaluation (APACHE II) scoring in a surgical intensive care unit. Crit Care Med 1992; 20(12):1681-7.

\begin{tabular}{|c|c|c|c|}
\hline \multicolumn{4}{|c|}{ AUTHORSHIP AND CONTRIBUTION DECLARATION } \\
\hline No. & Author(s) Full Name & Contribution to the paper & Author(s) Signature \\
\hline 1 & Ibtisam Ahmed Khan & Author & Ibt Ahmand \\
\hline 2 & Muhammad Kareem Ullah & $\begin{array}{l}\text { Data collection \& } \\
\text { discussion. }\end{array}$ & \\
\hline 3 & Saeed Mahmood & $\begin{array}{l}\text { Data collection \& } \\
\text { discussion. }\end{array}$ & Saced Malimood \\
\hline 4 & Adnan Sadiq Butt & Literature research. & \\
\hline 5 & Naeem Sarwar & Discussion. & Noar \\
\hline 6 & Bilal Afsar & Data collection. & Bilal Afser \\
\hline
\end{tabular}

